\title{
Avidin and Glucose Oxidase-non-covalently Functionalized Multi-walled Carbon Nanotubes: a New Analytical Tool for Building a Bienzymatic Glucose Biosensor
}

\author{
Pablo A. Gallay, ${ }^{[\mathrm{a}]}$ María D. Rubianes, ${ }^{[\mathrm{a}]}$ Fabiana A. Gutierrez, ${ }^{[\mathrm{a}]}$ and Gustavo A. Rivas ${ }^{*[\mathrm{a}]}$
}

\begin{abstract}
We report an innovative supramolecular architecture for bienzymatic glucose biosensing based on the non-covalently functionalization of multi-walled carbon nanotubes (MWCNTs) with two proteins, glucose oxidase (GOx) (to recognize glucose) and avidin (to allow the specific anchoring of biotinylated horseradish peroxidase (b-HRP)). The optimum functionalization was obtained by sonicating for $10 \mathrm{~min} 0.50 \mathrm{mg} \mathrm{mL}^{-1}$ MWCNTs in a solution of $2.00 \mathrm{mg} \mathrm{mL}^{-1} \mathrm{GOx}+1.00 \mathrm{mg} \mathrm{mL}^{-1}$ avidin prepared in $50: 50 \mathrm{v} / \mathrm{v}$ ethanol/water. The sensitivity to glucose for glassy carbon electrodes (GCE) modified with
\end{abstract}

MWCNTs-GOx-avidin dispersion and b-HRP (GCE/ MWCNTs-GOx-avidin/b-HRP), obtained from amperometric experiments performed at $-0.100 \mathrm{~V}$ in the presence of $5.0 \times 10^{-4} \mathrm{M}$ hydroquinone, was $(4.8 \pm$ $0.3) \mu \mathrm{AmM}^{-1}\left(\mathrm{r}^{2}=0.9986\right)$ and the detection limit was $1.2 \mu \mathrm{M}$. The reproducibility for 5 electrodes using the same MWCNTs/GOx-avidin dispersion was $4.0 \%$, while the reproducibility for 3 different dispersions and 9 electrodes was $6.0 \%$. The GCE/MWCNT-GOx-avidin/bHRP was successfully used for the quantification of glucose in a pharmaceutical product and milk.

Keywords: Multi-walled carbon nanotubes $\cdot$ non-covalent functionalization $\cdot$ glucose oxidase $\cdot$ avidin $\cdot$ glucose biosensor $\cdot$ bienzymatic biosensor

\section{Introduction}

In the last years, carbon nanomaterials have played a crucial role in the development of electrochemical (bio) sensors [1-4]. In particular, carbon nanotubes (CNTs) have demonstrated to be extremely useful due to their oustanding properties [5-9]. As a consequence of the strong interaction between tubes, the incorporation of CNTs in electrochemical transducers to obtain CNTsbased electrochemical (bio)sensors has been one of the major challenges. Different schemes to functionalize these nanostructures have been proposed [10-14]; among them, one interesting strategy has been the exfoliation of CNTs with biomolecules that not only disaggregate the nanostructures but also give to them particular properties that depends on the nature of the biomolecule [15-20]. We reported the non-covalent functionalization of MWCNTs with glucose oxidase (GOx) and the successful amperometric quantification of glucose using a glassy carbon electrode (GCE) modified with MWCNTs-GOx [17]. Recently, we proposed the use of avidin for the noncovalent functionalization of MWCNTs and the development of a multifunctional analytical platform (GCE/ MWCNTs-avidin) with application for the quantification of hydrogen peroxide using biotinylated horseradish peroxidase (b-HRP) [20].

In this work, we are reporting a new strategy for the preparation of a bienzymatic glucose biosensor through the non-covalent functionalization of MWCNTs with GOx and avidin and further bioaffinity interaction with bHRP. Bienzymatic amperometric biosensors coupling
HRP and GOx have been used as an interesting option for the quantification of glucose [21]. In this configuration, glucose is converted into gluconolactone by GOx while oxygen is reduced to hydrogen peroxide, which, in turn, is reduced to water by HRP. The detection of glucose is made either from the direct electron transfer of the prosthetic group of HRP or from the electroreduction of the oxidized form of a given HRP-redox mediator.

In the last years, several works have demonstrated the advantages of bienzymatic electrochemical glucose biosensors. Yang et al. [22] reported the submicromolar glucose biosensing by using a gold electrode modified with silver nanocubes (AgNCs) dispersed in chitosan, and HRP and GOx coimmobilized in chitosan, where AgNCs worked as electron transfer mediator. Rama et al. [23] designed a portable amperometric glucose biosensor using carbon-ink coated stainless-steel pins modified with GOx and HRP and ferrocyanide as electron transfer mediator. Xiang et al. [24] proposed a micromolar bienzymatic detection of glucose through the direct electron transfer

[a] P. A. Gallay, M. D. Rubianes, F. A. Gutierrez, G. A. Rivas INFIQC, Departamento de Fisicoquímica, Facultad de Ciencias Químicas, Universidad Nacional de Córdoba, Ciudad Universitaria, 5000 Córdoba, Argentina

Phone number: $+54-351-45353866$

Fax number: + 54-351-4334188

E-mail: fgutierrez@fcq.unc.edu.ar grivas@fcq.unc.edu.ar

Supporting information for this article is available on the WWW under https://doi.org/10.1002/elan.201900202 
of cytochrome c (cyt c) on gold nanoparticles/poly(aniline) nanospheres composite. Eguílaz et al. [25] described a glucose biosensor prepared by modification of GCE with MWCNTs dispersed in cyt $\mathrm{c}$ and casted with GOx using hydroquinone as redox mediator. Caro-Jara et al. [26] reported an amperometric bienzymatic biosensor based on GOx and HRP immobilized on mesoporous silica with hexagonal symmetry (MCM-41) using Nafion as co-immobilizing reagent and catechol as redox mediator. He et al. [27] proposed the use of HRP biosynthesized graphene with adjustable porous size as platform for the biocatalytic deposition of gold nanoparticles with nanomolar detection of glucose due to the synergistic effect of the porous graphene and gold nanoparticles. AmorGutiérrez et al. [28] described the use of a paper-based platform with carbon ink, GOx, HRP and potassium ferrocyanide adsorbed on the surface. A very sensitive biosensor based on the simultaneous entrapment of GOx and HRP during the HRP-catalyzed polymerization of noradrenaline in the presence of hydrogen peroxide was described by Liu et al. [29]. Wang et al. [30] proposed a bienzymatic sensor prepared with reduced graphene oxide as platform to immobilize HRP, GOx and the redox mediator poly(toluidine)blue.

We are reporting here a new avenue for the design of a bienzymatic glucose biosensor based on the use of a MWCNTs-GOx-avidin nanobiocomposite that allows efficient glucose biocatalytic oxidation, selective anchoring of HRP and effective electron transfer chain. In the following sections we present the optimization of the experimental conditions to prepare GCE/MWCNTs-GOx-avidin/b-HRP and the analytical performance of the resulting bienzymatic biosensor using hydroquinone as redox mediator.

\section{Experimental}

\subsection{Reagents}

Glucose oxidase (GOx) (type X-S, Aspergillus niger (EC 1.1.3.4), $50.000 \mathrm{U} / \mathrm{g}$ of solid, Catalog number G-7141), ascorbic acid (AA) and hydroquinone (HQ) were purchased from Sigma. Avidin (Product Number 43-4401) from egg and biotinylated horseradish peroxidase (bHRP) were obtained from Life Technology Invitrogen (USA). Multi-walled carbon nanotubes powder (MWCNT, diameter $(30 \pm 15) \mathrm{nm}$, length $1-5 \mu \mathrm{m})$ was obtained from NanoLab (USA). Other chemicals were reagent grade and used without further purification. The supporting electrolyte was $0.100 \mathrm{M}$ phosphate buffer solution $\mathrm{pH}$ 7.40. Ultrapure water $(\rho=18 \mathrm{M} \Omega . \mathrm{cm})$ from a Millipore-MilliQ system was used for preparing all the solutions.

\subsection{Apparatus and Procedure}

Electrochemical experiments were performed with a TEQ_4 potentiostat. A platinum wire and $\mathrm{Ag} / \mathrm{AgCl}, 3 \mathrm{M}$
$\mathrm{NaCl}$ (BAS) were used as counter and reference electrodes, respectively. All potentials are referred to the latter. A glassy carbon electrode (GCE) modified with MWCNTs-GOx-avidin dispersion was used as working electrode. A magnetic stirrer (BASi Cell stand) set at $800 \mathrm{rpm}$ and a stirring bar provided the convective transport during the amperometric measurements which were performed in a $0.100 \mathrm{M}$ phosphate buffer $\mathrm{pH} 7.40$ at $-0.100 \mathrm{~V}$ containing $5.0 \times 10^{-4} \mathrm{M}$ HQ. All measurements were carried out at room temperature.

\subsection{Preparation of GCE Modified with MWCNTs-GOx-avidin Dispersion}

\subsubsection{Preparation of MWCNT-GOx-avidin dispersion}

It was obtained by mixing $0.50 \mathrm{mg}$ MWCNTs with $1.0 \mathrm{~mL}$ of $1.0 \mathrm{mg} \mathrm{mL}^{-1}$ avidin $+2.0 \mathrm{mg} \mathrm{mL}^{-1}$ GOx solution (prepared in 50:50 v/v ethanol/water) followed by sonication for 10 min with ultrasonic bath.

\subsubsection{Modification of GCE with MWCNT-GOx-avidin (GCE/MWCNT-GOx-avidin)}

GCEs were first polished with alumina slurries of 1.0, 0.30 , and $0.05 \mu \mathrm{m}$ for $2 \mathrm{~min}$ each. After that, they were modified by dropping $20 \mu \mathrm{L}$ of the MWCNT-avidin-GOx dispersion on the top of the surface followed by the evaporation of the solvent at room temperature.

\subsubsection{Immobilization of $b-H R P$ at \\ GCE/MWCNT-GOx-avidin \\ (GCE/MWCNTs-GOx-avidin/b-HRP)}

GCE/MWCNTs-GOx-avidin was modified with b-HRP by dipping it in a $1.00 \mathrm{mg} \mathrm{mL}^{-1} \mathrm{~b}$-HRP solution (prepared in $0.100 \mathrm{M}$ phosphate buffer $\mathrm{pH} 7.40$ ) for $30 \mathrm{~min}$ at room temperature. Phosphate buffer solution with $0.010 \%$ Tween-20 was used as washing buffer after interaction with b-HRP to remove the unspecific binding. Figure 1 shows the different steps during the preparation of the bienzymatic biosensor.

\section{Results and Discussion}

\subsection{Direct Electrochemistry of GOx}

We evaluate the direct electron transfer of the GOx that supports the MWCNTs at GCE modified with MWCNTsGox-avidin. Figure 2A shows the potentiodynamic profiles for GCE/MWCNT-GOx-avidin in a deoxygenated $0.100 \mathrm{M}$ phosphate buffer solution $\mathrm{pH} 7.40$ at $0.100 \mathrm{Vs}^{-1}$. There is a typical pair of redox peaks due to the reduction of flavin adenine dinucleotide $(\mathrm{FAD})\left(\mathrm{E}_{\mathrm{pc}}=-0.522 \mathrm{~V}\right.$ and $\left.\mathrm{i}_{\mathrm{p}, \mathrm{c}}=26.1 \mu \mathrm{A}\right)$ and the corresponding reoxidation $\left(\mathrm{E}_{\mathrm{p}, \mathrm{a}}=\right.$ $-0.448 \mathrm{~V}$ and $\mathrm{i}_{\mathrm{p}, \mathrm{a}}=24.5 \mu \mathrm{A}$ ) with a formal potential of $-0.485 \mathrm{~V}$. The amount of electroactive enzyme at the electrode surface $(\Gamma)$, obtained from the charge of the 


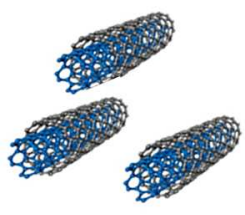

$0.50 \mathrm{mg} \cdot \mathrm{mL}^{-1}$ MWCNTS

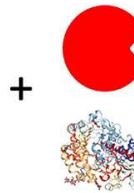

$1.0 \mathrm{mg} \cdot \mathrm{mL}^{-1}$

avidin

$2.0 \mathrm{mg} \cdot \mathrm{mL}^{-1}$

GOx

in ethanol $/ \mathrm{H}_{2} \mathrm{O}$

$(50: 50 \mathrm{v} / \mathrm{v})$
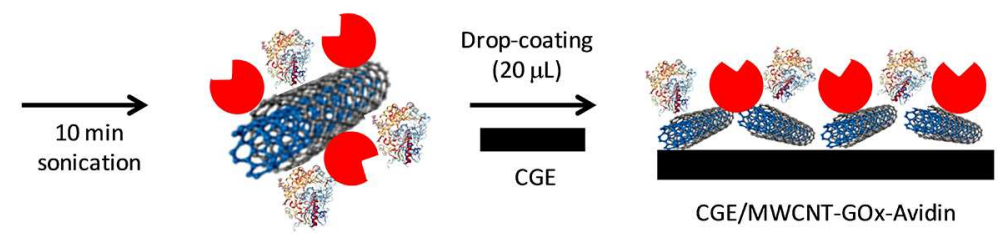

CGE/MWCNT-GOx-Avidin

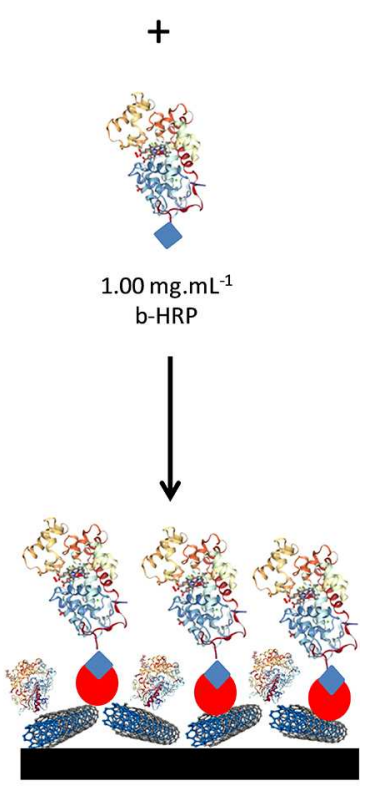

CGE/MWCNTs-GOx-avidin/b-HRP

Fig. 1. Scheme of the different steps for the preparation of the bienzymatic glucose biosensor (GCE/MWCNTs-GOx-avidin/b-HRP).

cathodic peak $(\mathrm{Q})$ according to $\mathrm{Q}=\mathrm{nFA \Gamma}(\mathrm{n}=2)$, was $3.3 \times 10^{-10}$ molcm $^{-2}$. The charge transfer rate constant $\left(\mathrm{k}_{\mathrm{s}}\right)$, calculated from the peak potential separation according to the Laviron model $[31,32]$, was $(1.7 \pm 0.2) \mathrm{s}^{-1}$ (considering a scan rate of $0.050 \mathrm{Vs}^{-1}$ and a charge transfer coefficient of 0.5). These values are in agreement with previous works reported in the literature [17], indicating that the presence of avidin does not prevent an efficient electron transfer between the FAD center of GOx and the electrode.

Figure 2B displays cyclic voltammograms for MWCNTS-Gox-avidin in $\mathrm{N}_{2}$-saturated $0.100 \mathrm{M}$ phosphate buffer solution $\mathrm{pH} 7.40$ containing $5.0 \times 10^{-4} \mathrm{M}$ ferrocene methanol and different concentrations of glucose: 0.00 (a), 100 (b) and 200 (c) mM. In the absence of glucose (a), the cyclic voltammogram shows the quasi-reversible peaks system due to the redox behavior of ferrocene methanol. In the presence of glucose, the anodic peak currents drastically increase whereas the cathodic ones decrease as a consequence of the biocatalytic activity of the GOx that supports the MWCNTs. This biocatalytic response indicates that GOx remains active after sonication in ethanol/ water and non-covalent interaction with MWCNTs in the presence of avidin.

\subsection{Optimization of the Experimental Conditions for the Preparation of GCE/MWCNTs-GOx-avidin/b-HRP Biosensor}

The effect of the sonication time during the preparation of the dispersion on the amperometric response to hydrogen peroxide at $-0.100 \mathrm{~V}$ was comparatively evaluated for GCE modified with MWCNTs-avidin and MWCNTsGOx-avidin dispersions. The sensitivity to hydrogen peroxide for GCE/MWCNTs-avidin was enhanced around $30 \%$ when the sonication time increased from 10 to 20 min dispersion. At variance with this behavior, in the case of GCE modified with MWCNTs-GOx-avidin prepared by sonicating 10,15 and $20 \mathrm{~min}$, the sensitivities showed almost no changes $\left((2.60 \pm 0.07) \mu \mathrm{AmM}^{-1},(2.6 \pm\right.$ $0.1) \mu \mathrm{AmM}^{-1}$ and $(2.41 \pm 0.04) \mu \mathrm{AmM}^{-1}$, for 10,15 and $20 \mathrm{~min}$, respectively), and were very similar to the one obtained for MWCNTs-avidin after $20 \mathrm{~min}$ sonication. These results demonstrate that the incorporation of GOx in the dispersion makes more favorable the disaggregation of the carbon nanostructures, evidencing, in this way, the double role of GOx as exfoliating agent of MWCNTs and biorecognition element for further glucose biosensing. Therefore, the selected sonication time was $10 \mathrm{~min}$.

In order to evaluate not only the exfoliation of the nanostructures but also the biocatalytic activity of the resulting nanobiocomposite, we investigate the effect of 

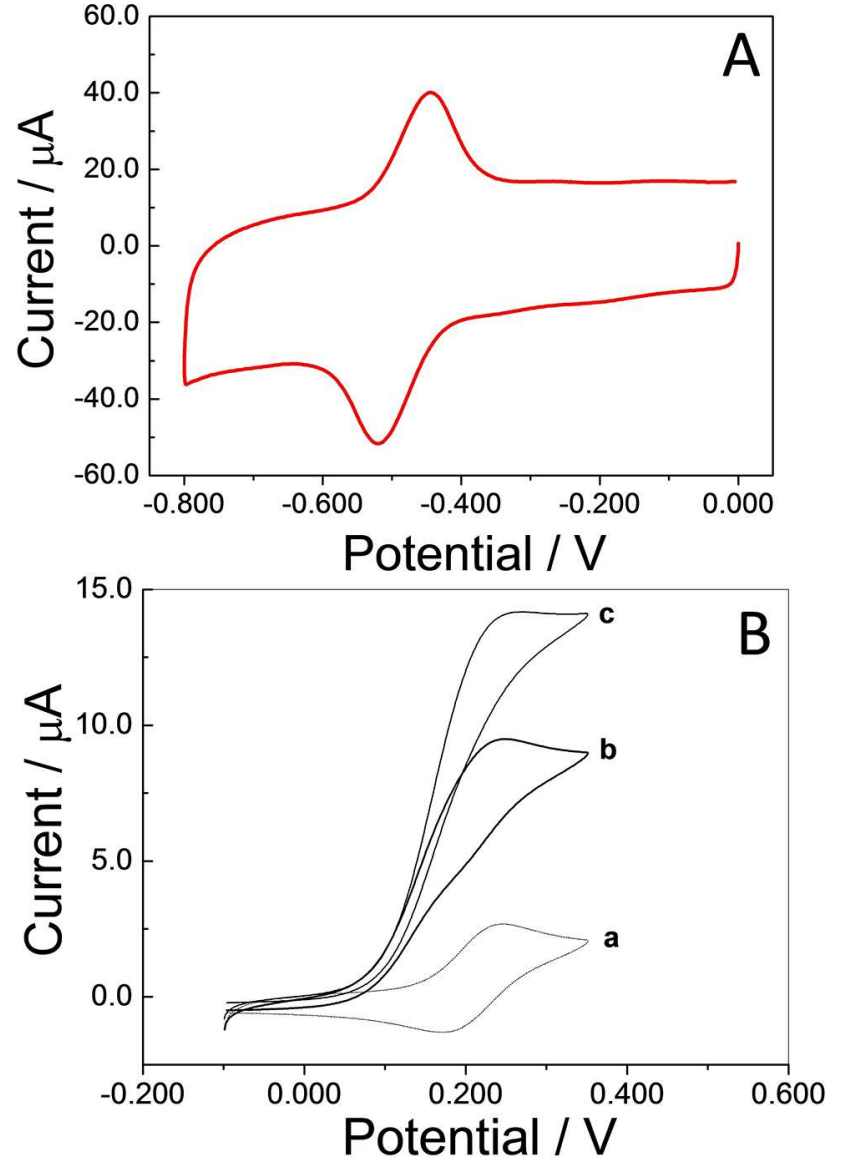

Fig. 2. (A). Cyclic voltamogram obtained at GCE modified with MWCNTS-GOx-avidin in a $0.050 \mathrm{M}$ phosphate buffer solution $\mathrm{pH}$ 7.40. Scan rate: $0.100 \mathrm{Vs}^{-1}$. Conditions for the preparation of the dispersion: $0.50 \mathrm{mg} \mathrm{mL}^{-1}$ MWCNTs in $1.0 \mathrm{mg} \mathrm{mL}^{-1}$ avidin and $2.0 \mathrm{mg} \mathrm{mL}^{-1} \mathrm{GOx}$ prepared in $50 / 50 \mathrm{v} / \mathrm{v}$, ethanol/water sonicated for $10 \mathrm{~min}$. (B) Cyclic voltammograms for $5.0 \times 10^{-4} \mathrm{M}$ ferrocene methanol in a deoxygenated $0.100 \mathrm{M}$ phosphate buffer solution pH 7.40 obtained at GCE/MWCNTs-GOx-avidin after the addition of different concentrations of glucose: 0 (a), 100 (b), and 200 (c) mM. Scan rate: $0.005 \mathrm{~V} \mathrm{~s}^{-1}$.

GOx concentration for dispersing $0.50 \mathrm{mg} \mathrm{mL}^{-1}$ MWCNTs in the presence of $1.00 \mathrm{mg} \mathrm{mL}^{-1}$ avidin after $10 \mathrm{~min}$ sonication from the amperometric response to glucose. As Figure 3 shows, the sensitivity to glucose increases with the amount of GOx up to $2.00 \mathrm{mg} \mathrm{mL}^{-1}$. For higher GOx concentrations, the sensitivity decreases due to the blockage of the electrode surface by the non-conductive protein. Therefore, the selected GOx concentration was $2.0 \mathrm{mg} \mathrm{mL}^{-1}$ as the best compromise between linear range, reproducibility and sensitivity.

The influence of b-HRP concentration (from 0.50 to $2.00 \mathrm{mg} \mathrm{mL}^{-1}$ ) used for the construction of $\mathrm{GCE} /$ MWCNT-avidin-GOx/b-HRP was also investigated from the amperometric response to glucose (results not shown). The sensitivity to glucose increases with b-HRP concentration up to $1.0 \mathrm{mg} \mathrm{mL}^{-1}$, to decrease thereafter due to the increment of a non-conductive protein at the

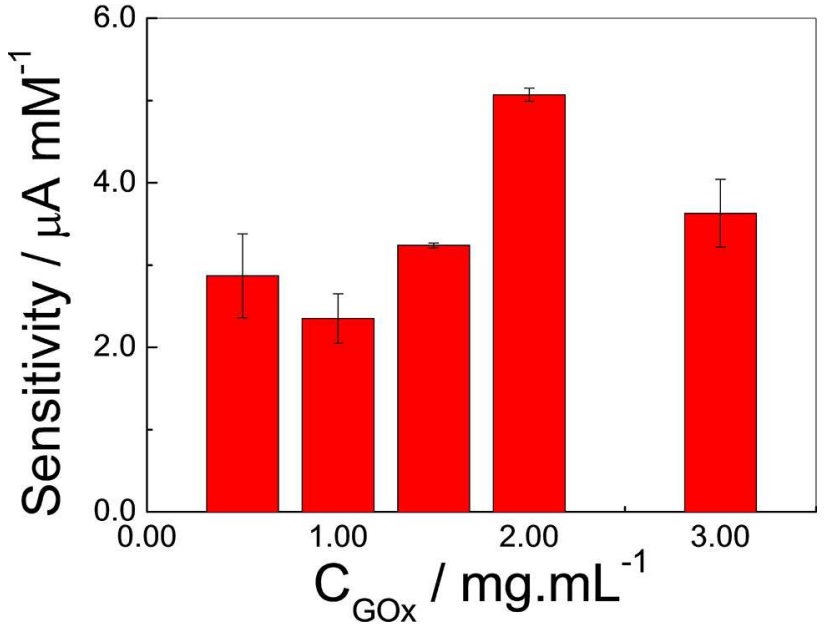

Fig. 3. Sensitivities to glucose obtained from amperometric recordings at GCE modified with MWCNTs-GOx-avidin/b-HRP prepared with different concentrations of GOx. Working potential: $-0.100 \mathrm{~V}$. Hydroquinone: $5.0 \times 10^{-4} \mathrm{mM}$. Supporting electrolyte: $0.100 \mathrm{M}$ phosphate buffer solution $\mathrm{pH} 7.40$. b-HRP immobilization: $30 \mathrm{~min}$ interaction of GCE/MWCNTs-GOx-avidin with $1.0 \mathrm{mg} \mathrm{mL}^{-1} \mathrm{~b}-\mathrm{HRP}$ solution.

electrode surface. Therefore, $1.0 \mathrm{mg} \mathrm{mL}^{-1}$ b-HRP was selected to obtain the bienzymatic glucose biosensor.

The concentration of $\mathrm{HQ}$ is an important parameter when selecting the optimal conditions for the amperometric transduction of the glucose biorecognition event since the base-line of the current-time profiles is related to the concentration of the redox mediator. Table 1 displays the

Table 1. displays the effect of hydroquinone concentration on the sensitivity of GCE/MWCNTs-GOx-avidin/b-HRP to glucose at $-0.100 \mathrm{~V}$.

\begin{tabular}{ll}
\hline $\begin{array}{l}\text { HQ concentration } \\
(\mathrm{mM})\end{array}$ & $\begin{array}{l}\text { Sensitivity } \\
\left(\mu \mathrm{AmM} \mathrm{mM}^{-1}\right)\end{array}$ \\
\hline 0.10 & $4.44 \pm 0.09$ \\
0.25 & $4.70 \pm 0.08$ \\
0.50 & $4.80 \pm 0.06$ \\
1.00 & $4.7 \pm 0.2$ \\
\hline
\end{tabular}

effect of HQ concentration on the sensitivity of GCE/ MWCNTs-GOx-avidin/b-HRP to glucose at $-0.100 \mathrm{~V}$. The sensitivity increases when the concentration of $\mathrm{HQ}$ increases from $1.0 \times 10^{-4} \mathrm{M}$ to $5.0 \times 10^{-4} \mathrm{M}$ to level off thereafter. Therefore, considering that the concentration of the redox mediator has to be high enough to improve the sensitivity, but not too high to avoid high values of base-line currents, we selected $5.0 \times 10^{-4} \mathrm{M}$ as the best compromise between sensitivity, reproducibility and baseline current. 


\subsection{Analytical Performance of the Biosensor}

Figure 4A displays the amperometric recording obtained at GCE/MWCNTs-GOx-avidin/b-HRP at $-0.100 \mathrm{~V}$ in the
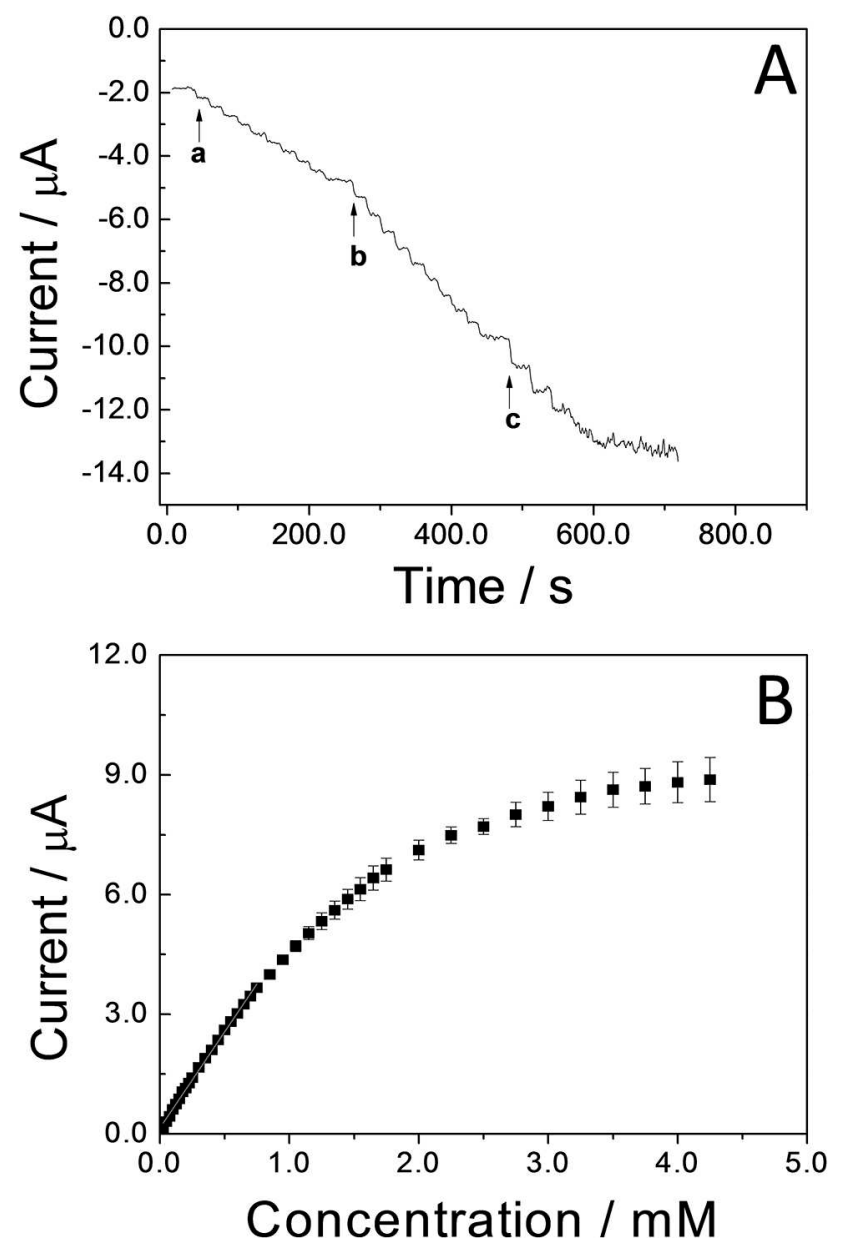

Fig. 4. (A) Amperometric recording obtained at GCE/MWCNTsGOx-avidin/b-HRP for successive additions of glucose: a) $50 \mu \mathrm{M}$, b) $100 \mu \mathrm{M}$ and c) $250 \mu \mathrm{M}$. (B) Calibration plot obtained from experiments like the one shown in (A) using different glucose concentration. Other conditions: as in Figure 3. The average currents were obtained using 5 biosensors prepared with the same MWCNTs-GOx-avidin dispersion.

presence of $5.0 \times 10^{-4} \mathrm{M} \mathrm{HQ}$ for successive additions of glucose. A well-defined and fast amperometric response, due to the reduction of the quinone produced during HRP regeneration, is obtained after the addition of micromolar levels of glucose. Figure 4B depicts the corresponding calibration plot obtained for successive additions of $25 \mu \mathrm{M}$ glucose at GCE/MWCNTs-GOxavidin/b-HRP. There is a linear relationship between the analytical signal and glucose concentration between 25 and $750 \mu \mathrm{M}$, with a sensitivity of $(4.8 \pm 0.3) \mu \mathrm{AmM}^{-1}$ and a detection limit of $1.2 \mu \mathrm{M}$ (obtained as $3 \mathrm{x}$ standard deviation of the blank signal/sensitivity). It is important to mention that the sensitivity obtained from amperometric experiments using GCE/MWCNTs-GOx/b-HRP was $(1.1 \pm 0.2) \mu \mathrm{AmM}^{-1}$, that is, almost 4.5 times lower than the sensitivity reached with GCE/MWCNTs-GOx-avidin/ b-HRP. These results demonstrate once more that avidin maintains the biorecognition properties even after the drastic treatment during the preparation of the dispersion and that b-HRP is specifically-anchored at the proposed nanoarchitecture. Similar amperometric experiments at $-0.100 \mathrm{~V}$ performed with GCE/MWCNTs-GOx and GCE/MWCNTs-GOx-avidin gave a negligible response (not shown).

Table 2 summarizes the analytical characteristics of the most representative bienzymatic glucose biosensors reported in the last years. Our biosensor showed detection limits lower than most of the electrochemical biosensors reported in the table, with exception of $[22,27,29]$. The biosensors reported in [22] (GOx-HRP/AgNCs-CS/Au) and [29] (PNA-HRP-GOx/Pt) present the advantage of being platforms where the enzymes and the redox mediator are integrated at the electrode surface. The synergism of the two nanomaterials present in the biosensor reported in ref. [27] (AuNPs and porous graphene) is the responsible for the improved detection limits, although the platform presents the disadvantage that the process to obtain the porous graphene is time consuming. No practical applications in real samples were reported for this bioelectrode. Regarding the non-electrochemical biosensors, some of them present lower detection limits than our biosensor, although in several cases the redox mediator is a highly toxic compound. There are two sensors $[37,39]$ that are not bienzymatic biosensors because they involved only one enzyme [39] or no enzymes at all [37]. However, they were included in this comparative table because they are interesting examples of enzyme-mimetic based-sensors. Quiao et al. [37] proposed the use of nanostructures with peroxidase and GOx like activity, with very good performance, although no real samples were evaluated. The approach described in ref. [39] represents a very innovative strategy and used GOx and a nanozyme with peroxidase-like activity $(\mathrm{CuS})$.

The reproducibility for 5 biosensors prepared with the same MWCNTs-avidin-GOx dispersion was $4.0 \%$ while the reproducibility for 3 dispersions using 9 biosensors was $6.0 \%$. Figure SI-1 depicts amperometric recordings obtained after the addition of $2.5 \times 10^{-4} \mathrm{M}$ glucose followed by the addition of different sugars: galactose, lactose, maltose and fructose (all of them $2.5 \times 10^{-4} \mathrm{M}$ ). No interference was observed in any case. Considering that the concentration of ascorbic acid depends on the sample under investigation, we evaluate the interference of two ascorbic acid concentrations, $7.5 \times 10^{-6} \mathrm{M}$ and $1.5 \times$ $10^{-5} \mathrm{M}$, in the presence of $7.5 \times 10^{-4}$ glucose. The corresponding interference percentages were $6.7 \%$ and $8.3 \%$, respectively. The biosensor was challenged with two real samples: a nasal spray "Allennys", which contains glucose as an excipient, and milk (La Serenísima). The concentration of glucose in the nasal spray, obtained after 8 determinations, was $(2.7 \pm 0.1) \mathrm{mg} / \mathrm{dose}$ indicating an 
Table 2. Analytical performance of bienzymatic glucose biosensors.

\begin{tabular}{|c|c|c|c|c|c|c|c|}
\hline Sensor & Transduction & Mediator & Sensitivity & DL & $\begin{array}{l}\mathrm{LR} \\
\mu \mathrm{M}\end{array}$ & Real sample & Ref. \\
\hline GOx-CS-HRP/AgNCs-CS/Au & Amperometric & AgNCs & - & 0.69 & $10-1500$ & serum & {$[22]$} \\
\hline $\begin{array}{l}\text { GOD + HRP/MWCNT } \\
\text { pin-devices }\end{array}$ & Amperometric & ferrocyanide & - & 30 & $\begin{array}{l}50 \times 10^{3}- \\
1.000 \times 10^{6}\end{array}$ & $\begin{array}{l}\text { honey } \\
\text { orange juice }\end{array}$ & [23] \\
\hline GOx/Cyt c/GNPs/PANS/GCE & Amperometric & - & $\begin{array}{l}63.1 \\
\mu \mathrm{AmM} \mathrm{M}^{-1} \mathrm{~cm}^{-2}\end{array}$ & 10 & 10 to 3200 & human serum & {$[24]$} \\
\hline $\begin{array}{l}\text { Nafion/GOx/Cyt c- } \\
\text { MWCNTs/GCE }\end{array}$ & Amperometric & HQ & $96 \mu \mathrm{A} \cdot \mathrm{M}^{-1}$ & 8 & $100-1000$ & $\begin{array}{l}\text { Comercial } \\
\text { beverages }\end{array}$ & {$[25]$} \\
\hline $\begin{array}{l}\text { Nafion/(GOx/HRP)/ } \\
(\mathrm{MCM}-41) / \mathrm{GCE}\end{array}$ & Amperometric & catechol & $467 \mu \mathrm{A} \cdot \mathrm{M}^{-1}$ & 8.6 & $25-100$ & $\begin{array}{l}\text { Pharmaceutical } \\
\text { formulations }\end{array}$ & {$[26]$} \\
\hline AuNPs/GOx-PGR/GCE & Voltammetric & - & $755 \mu \mathrm{AmM}^{-1}$ & 0.05 & $0.25-27.5$ & & {$[27]$} \\
\hline GOx-HRP/SPCE & Amperometric & ferrocyanide & - & 120 & $300-1500$ & - & {$[28]$} \\
\hline PNA-HRP-GOx/Pt & Amperometric & PNA & $\begin{array}{l}628.4 \\
\mu \mathrm{AmM}^{-1} \mathrm{~cm}^{-2}\end{array}$ & 0.08 & $0.50-420$ & Blood serum & [29] \\
\hline GCE/RGO/pTB-HRP-GOx & Amperometric & pTB & - & 50 & $80-3000$ & - & {$[30]$} \\
\hline $\begin{array}{l}\text { PAA brushes- } \mathrm{SiO}_{2} \mathrm{NPs} / \\
\text { (GOx/HPR) }\end{array}$ & UV/Visible & ABTS & - & 0.04 & 0.167 to 20 & $\begin{array}{l}\text { diluted human } \\
\text { serum }\end{array}$ & {$[33]$} \\
\hline $\mathrm{LOC} /(\mathrm{GOx} / \mathrm{HPR})$ & $\begin{array}{l}\text { Optical } \\
\text { Electrochemical }\end{array}$ & ABTS & - & $\begin{array}{l}230 \\
64\end{array}$ & $1600-2000$ & - & {$[34]$} \\
\hline $\begin{array}{l}\mathrm{GOx} \& \mathrm{HRP}-\mathrm{Cu}_{3}\left(\mathrm{PO}_{4}\right)_{2} \cdot 3 \mathrm{H}_{2} \mathrm{O} \\
\text { nanoflowers }\end{array}$ & UV/Visible & TMB & - & 0.2 & $0-50$ & - & {$[35]$} \\
\hline $\begin{array}{l}\text { GOx }+ \text { HRP/PHEMA/ } \\
\text { Glass chip }\end{array}$ & UV/Visible & ABTS & - & 60 & - & - & {$[36]$} \\
\hline $\mathrm{FeSe}-\mathrm{Pt} @ \mathrm{SiO}_{2} \mathrm{NPs}$ & $\begin{array}{l}\text { Colorimetric } \\
\text { detections }\end{array}$ & TMB & - & 0.00227 & $0.00227-1440$ & - & {$[37]$} \\
\hline $\begin{array}{l}\text { FHGB droplets } \\
\text { (GOx-HRP/PAA/CDs) }\end{array}$ & Fluorescence & - & - & 51.6 & Up to 30000 & $\begin{array}{l}\text { human blood } \\
\text { serum }\end{array}$ & {$[38]$} \\
\hline $\mathrm{GOx}-\mathrm{CuS}$ & $\begin{array}{l}\text { Colorimetric } \\
\text { detections }\end{array}$ & TMB & - & 0.13 & Up to 110 & blood & [39] \\
\hline CNT-HRP\&CNT-GOD & Colorimetric & TMB & $0.16 \mu \mathrm{A} \cdot \mathrm{M}^{-1}$ & 0.3 & $1-100$ & $\begin{array}{l}\text { like human } \\
\text { serum and } \\
\text { human serum } \\
\text { albumin }\end{array}$ & {$[40]$} \\
\hline $\begin{array}{l}\text { b-HRP/avidin-GOx-MWCNT/ } \\
\text { GCE }\end{array}$ & Amperometric & HQ & $4.8 \mu \mathrm{A} \cdot \mathrm{mM}^{-1}$ & 1.2 & $50-500$ & $\begin{array}{l}\text { medicine and } \\
\text { milk }\end{array}$ & $\begin{array}{l}\text { This } \\
\text { work }\end{array}$ \\
\hline
\end{tabular}

excellent correlation with the value reported by the laboratory $(2.75 \mathrm{mg} / \mathrm{dose})$. The glucose concentration in milk, obtained as average of 7 determinations, was $(2.1 \pm$ $0.1) \mathrm{gmL}^{-1}$, results that present an error of $10.6 \%$ compared to the value reported by the company $\left(1.9 \mathrm{gmL}^{-1}\right)$.

\section{Conclusions}

In summary, we proposed an innovative supramolecular nanoarchitecture based on the use of a nanobiocomposite integrated by MWCNTs non-covalently functionalized with GOx and avidin, proteins that not only exfoliate the CNTs but also give to them biorecognition properties for the biocatalytic oxidation of glucose (through GOx) and bioaffinity interaction with b-HRP (through avidin), even despite the drastic conditions to prepare the dispersion. The platform made possible the efficient and competitive bi-enzymatic glucose biosensing through the intimate contact of MWCNTs with GOx and HRP that allows an efficient glucose and hydrogen peroxide biorecognition, and ensures the fast charge transfer of the redox mediator. The proposed platform demonstrated once more the advantages of the rational selection of the functionalizing agent and the importance of using biomolecules to exfoliate and support the CNTs in electrochemical biosensors.

\section{Acknowledgements}

The authors thank CONICET, SECyT-UNC and ANPCyT for the financial support. P. G. thanks CONICET for the fellowship.

\section{References}

[1] J. N. Tiwari, V. Vij, K. C. Kemp, K. S. Kim, ACS Nano. 2016, 10, 46-80.

[2] L. Kong, W. Chen, Adv. Mater. 2014, 26, 1025-1043.

[3] N. Baig, M. Sajid, T. A. Saleh, TrAC Trends Anal. Chem. 2019, 111, 47-61.

[4] K. Bala, D. Sharma, N. Gupta, ChemElectroChem. 2019, 6, 274-288 
[5] I. V. Zaporotskova, N. P. Boroznina, Y. N. Parkhomenko, L. V. Kozhitov, Mod. Electron. Mater. 2016, 2, 95-105.

[6] G. A. Rivas, M. C. Rodríguez, M. D. Rubianes, F. A. Gutierrez, M. Eguílaz, P. R. Dalmasso, E. N. Primo, C. Tettamanti, M. L. Ramírez, A. Montemerlo, P. Gallay, C. Parrado, Appl. Mater. Today 2017, 9, 566-588.

[7] G. Maduraiveeran, M. Sasidharan, V. Ganesan, Biosens. Bioelectron. 2018, 103, 113-129.

[8] S. Gupta, C. N. Murthy, C. R. Prabha, Int. J. Biol. Macromol. 2018, 108, 687-703.

[9] Z. Zhu, Nano-Micro Lett. 2017, 9, 1-24.

[10] A. Setaro, J. Phys. Condens. Matter. 2017, 29, 0-28.

[11] M. S. Ata, R. Poon, A. M. Syed, J. Milne, I. Zhitomirsky, Carbon 2018, 130, 584-598.

[12] D. Baskaran, J. W. Mays, M. S. Bratcher, Chem. Mater. 2005, 17, 3389-3397.

[13] S. Mallakpour, S. Soltanian, RSC Adv. 2016, 6, 109916109935.

[14] Y. Zhou, Y. Fang, R. P. Ramasamy, Sensors 2019, 19, 902930.

[15] M. Eguílaz, A. Gutiérrez, G. Rivas, Sens. Actuators B Chem. 2016, 225, 74-80.

[16] M. B. Barbosa, E. M. D. N. Martins, T. F. Teixeira, R. D. E. Carvalho, J. P. Coelho, R. R. Resende, E. F. Oliveira, A. P. Santos, A. S. R. D. Andrade, Colloids Surf. B: Biointerfaces. 2019, 175, 175-183.

[17] F. Gutierrez, M. D. Rubianes, G. A. Rivas, Sens. Actuators B Chem. 2012, 161, 191-197.

[18] E. N. Primo, P. Cañete-Rosales, S. Bollo, M. D. Rubianes, G. a. Rivas, Colloids Surf. B Biointerfaces. 2013, 108, 329336.

[19] E. N. Primo, M. B. Oviedo, C. G. Sánchez, M. D. Rubianes, G. A. Rivas, Bioelectrochemistry. 2014, 99, 8-16.

[20] F. A. Gutierrez, M. D. Rubianes, G. A. Rivas, Analytica Chimica Acta. 2019 in press.

[21] J. Wang, Chem. Rev. 2008, 108, 814-825.

[22] P. Yang, L. Wang, Q. Wu, Z. Chen, X. Lin, Sens. Actuators B 2014, 194, 71-78.

[23] E. C. Rama, A. Costa-García, M. Teresa Fernández-Abedul, Biosens. Bioelectron. 2017, 88, 34-40.
[24] C. Xiang, Y. Zou, S. Qiu, L. Sun, F. Xu, H. Zhou, Talanta. 2013, 110, 96-100.

[25] M. Eguílaz, C. J. Venegas, A. Gutiérrez, G. A. Rivas, S. Bollo, Microchem. J. 2016, 128, 161-165.

[26] N. Caro-Jara, R. Mundaca-Uribe, C. Zaror-Zaror, J. Carpinelli-Pavisic, M. Aranda-Bustos, C. Peña-Farfal, Electroanalysis 2013, 25, 308-315.

[27] Y. He, J. Zheng, B. Wang, H. Ren, Materials 2017, 10, 1139.

[28] O. Amor-Gutiérrez, E. Costa Rama, A. Costa-García, M. T. Fernández-Abedul, Biosens. Bioelectron. 2017, 93, 40-45.

[29] L. Liu, C. Chen, C. Chen, X. Kang, H. Zhang, Y. Tao, Q. Xie, S. Yao, Talanta. 2019, 194, 343-349.

[30] F. Wang, W. Gong, L. Wang, Z. Chen, Microchim. Acta 2015, 182, 1949-1956.

[31] E. Laviron, J. Electroanal. Chem. 1979, 101, 19-28.

[32] N. Jia, L. Liu, Q. Zhou, L. Wang, M. Yan, Z. Jiang, Electrochim. Acta 2005, 51, 611-618.

[33] Y. Zhao, Y. Wang, X. Zhang, R. Kong, L. Xia, F. Qu, Talanta. 2016, 155, 265-271.

[34] B. Ibarlucea, X. Munoz-Berbel, P. Ortiz, S. Büttgenbach, C. Fernández-Sánchez, A. Llobera, Sens. Actuators B 2016, 237, $16-23$.

[35] J. Sun, J. Ge, W. Liu, M. Lan, H. Zhang, P. Wang, Z. Niu, Nanoscale. 2014, 6, 255-262.

[36] F. Costantini, R. Tiggelaar, S. Sennato, F. Mura, S. Schlautmann, F. Bordi, C. Manetti, Analyst. 2013, 138, 50195024.

[37] F. Qiao, Z. Wang, K. Xu, S. Ai, Analyst. 2015, 140, 66846691.

[38] H. Park, S. Y. Park, ACS Appl. Mater. Interfaces. 2018, 10, 30172-30179.

[39] X. Niu, Y. He, J. Pan, X. Li, F. Qiu, Y. Yan, L. Shi, H. Zhao, M. Lan, Anal. Chim. Acta 2016, 947, 42-49.

[40] C. Wang, Q. Wang, R. Tan, Analyst. 2018, 143, 4118-4127. 


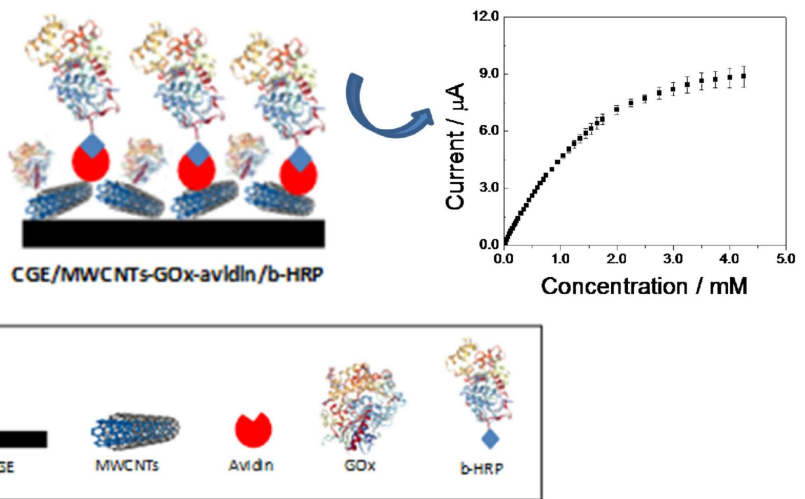

P. A. Gallay, M. D. Rubianes,

F. A. Gutierrez*, G. A. Rivas*

$1-8$

Avidin and Glucose Oxidase-noncovalently Functionalized Multiwalled Carbon Nanotubes: a New Analytical Tool for Building a Bienzymatic Glucose Biosensor 